\title{
Os saberes em ginástica rítmica: do mapeamento da produção à formação inicial em educação física ${ }^{1}$
}

\section{The knowledge in rhythmic gymnastics: the mapping of production of initial training in physical education}

\section{Conocimientos en gimnasia rítmica: del mapa de la producción al formacion inicial en educación física}

\author{
iD Murilo Eduardo dos Santos Nazário \\ Universidade Vila Velha, Vila Velha, Espírito Santo, Brasil \\ e-mail: murilo.nazario@uvv.com \\ iD Nicole Cerutti Guirlinzoni \\ Universidade Vila Velha, Vila Velha, Espírito Santo, Brasil
}

\begin{abstract}
Resumo: Esta pesquisa organiza-se em torno das seguintes questões: como o estado do conhecimento sobre a Ginástica Rítmica (GR) pode contribuir para o desenvolvimento de novos estudos sobre essa temática? Os resultados encontrados forneceram as bases para a segunda questão, responsável por orientar a pesquisa de campo, assim definida: como graduandos em educação física se relacionam com os saberes profissionais para atuação com/na GR? O objetivo é analisar e discutir o (não) lugar que a GR ocupa na trajetória de formação inicial em Educação Física. Os resultados sinalizam para o distanciamento em relação aos saberes dessa modalidade, provenientes da ausência de experiências sistematizadas de ensino aprendizagem e treinamento com essa modalidade antes e durante a graduação.
\end{abstract}

Palavras-chave: Ginástica Rítmica. Formação Inicial. Educação Física.

10 presente estudo não contou com nenhum apoio financeiro. 


\begin{abstract}
This research is organized around the following questions: how can the state of knowledge about Rhythmic Gymnastics (GR) contribute to the development of new studies on this theme? The results found provided the basis for the second question, responsible for guiding the field research. Thus defined: how do undergraduates in physical education relate to professional knowledge for work with/in the GR? The objective is to analyze and discuss the (non) place that the GR occupies in the trajectory of initial training in Physical Education. The results indicate the distancing from the knowledge of this modality, coming from the absence of systematized experiences of teaching learning and training with this modality before and during graduation.
\end{abstract}

Keywords: Rhythmic Gymnastics, Graduation, Physical Education.

Resumen: Esta investigación se organiza en torno a las siguientes preguntas: ¿cómo puede el estado de conocimiento sobre gimnasia rítmica (GR) contribuir al desarrollo de nuevos estudios sobre este tema? Los resultados encontrados proporcionaron la base para la segunda pregunta, responsable de guiar la investigación de campo. Así definido: ¿cómo se relacionan los estudiantes de educación física con los conocimientos profesionales para el trabajo con / en el GR? El objetivo es analizar y discutir el (no) lugar que el GR ocupa en la trayectoria de la formación inicial en Educación Física. Los resultados indican el distanciamiento del conocimiento de esta modalidad, derivado de la ausencia de experiencias sistematizadas de enseñanza de aprendizaje y formación con esta modalidad antes y durante la graduación

Palabras clave: Gimnasia Rítmica. Formación inicial. Educación Física.

Submetido em: 22-07-2019

Aceito em: 23-06-2020 
Os saberes em ginástica rítmica: do mapeamento da produção à formação inicial... Murilo Eduardo dos Santos Nazário • Nicole Cerutti Guirlinzoni

\section{Introdução}

A Ginástica Rítmica (GR), como modalidade esportiva, ainda é recente, tendo conquistado espaço no cenário internacional a partir de meados do século XX (SANTOS, LOURENÇO, GAIO; 2010). Segundo Gaio (2007), quatro correntes influenciaram o desenvolvimento da GR, sendo elas: as Artes Cênicas, a Dança, a Música e a Pedagogia. Essas composições levaram à criação de uma nova modalidade inovadora e dinâmica que se diferenciava dos movimentos masculinos em que se percebia o predomínio da força, dando origem à GR.

No contexto nacional a modalidade foi introduzida pela professora húngara Ilona Peuker, na cidade do Rio de Janeiro, em 1956, onde foi criada a primeira equipe brasileira de Ginástica Rítmica, o Grupo Unido de Ginástica (GUG) (SANTOS, LOURENÇO, GAIO; 2010).

Na produção científica a GR tem sido discutida há pouco tempo e, segundo Pereira et al. (2012), com ênfase em temáticas relacionadas á saúde, fitness e esporte. No entanto, recentemente tem se averiguado o desenvolvimento de pesquisas com aproximações epistemológicas ao campo da educação, formação humana e história, possibilitando compreender outras interfaces da GR.

Em mapeamento realizado na produção nacional, Simões et al. (2016), ao analisarem 340 artigos produzidos entre os anos de 2000 a 2015, abrangendo diferentes ramificações das ginásticas, identificaram como temáticas recorrentes nesses estudos: saúde, pedagogia do esporte e fisiologia. Todavia, os autores reforçam o objetivo central desse tipo de estudos, ou seja, colaborar para a ampliação de novas pesquisas na área, principalmente para sanar as possíveis lacunas existentes.

Nesse sentido, realizou-se um novo mapeamento da produção, porém com direcionamento específico para modalidade GR e avançou-se para pesquisas no cenário internacional, sendo uti- 
Os saberes em ginástica rítmica: do mapeamento da produção à formação inicial... Murilo Eduardo dos Santos Nazário • Nicole Cerutti Guirlinzoni

lizado um corpus documental de 28 artigos provenientes de 17 periódicos avaliados em A1 no web-qualis 2013/2016, cujas temáticas discutidas, encontradas com maior recorrência, referem-se à iniciação esportiva, lesões, treinamento físico e nutrição esportiva.

As incipiências identificadas na produção analisada possibilitam a construção de novos estudos que contribuam para o avanço do campo da GR. Uma dessas ausências refere-se à formação inicial em Educação Física e ao direcionamento para atuação com/ na GR, temática de suma relevância, pois é necessário compreender como ocorrem os percursos de formação dos possíveis profissionais que se responsabilizarão pela organização do processo de ensino-aprendizagem e treinamento dessa modalidade.

Do mesmo modo, é fundamental identificar os tipos de saberes a serem mobilizados, utilizados e aplicados na atuação profissional nessa área. Ainda, pode-se analisar a trajetória de formação percorrida por esse sujeito ao longo da graduação em educação física e o modo como ele se aproxima ou se distancia da GR. Nesse sentido, opera-se com subsídios teóricos de Tardiff (2002) e Charlot (2000), pois o fazer docente no caso das práticas corporais, entre elas a GR, a partir da relação com os saberes, não se restringe ao âmbito escolar, uma vez que os saberes docentes são plurais e dinâmicos.

Com isso, professor é aquele que "sabe alguma coisa e cuja função é transmitir esse saber a outras pessoas" (TARDIFF, 2002, p. 31). Do mesmo modo, esse sujeito estabelece possibilidades de relações com os saberes, principalmente com a figura do aluno, pois “adquirir saber permite assegurar-se um certo domínio do mundo no qual se vive, comunicar-se com outros seres e partilhar o mundo com eles, viver certas experiências e, assim, tornar-se maior, mais seguro de si, mais independente" (CHARLOT, 2000, p. 60).

Esta pesquisa organiza-se em torno da seguinte questão: como o estado do conhecimento sobre a GR pode contribuir para o desenvolvimento de novos estudos sobre essa temática? Os resultados encontrados, principalmente no que tange às ausên- 
Os saberes em ginástica rítmica: do mapeamento da produção à formação inicial... Murilo Eduardo dos Santos Nazário • Nicole Cerutti Guirlinzoni

cias, tencionaram para a segunda questão, responsável por orientar a pesquisa de campo, assim definida: como graduandos em Educação Física se relacionam com os saberes profissionais para atuação com/na GR? Objetiva-se analisar e discutir o (não) lugar que a GR ocupa na trajetória de formação inicial em Educação Física. Almeja-se ainda sinalizar as limitações e possibilidades de práticas científicas em GR realizadas de modo combinado entre estado do conhecimento e pesquisa empírica.

\section{Metodologia}

O presente estudo foi dividido em duas etapas. Na primeira mapeou-se e discutiu-se a produção científica no campo da Ginástica Rítmica em âmbito internacional, pois, na literatura nacional, Simões et al. (2016) desenvolveram uma pesquisa de natureza similar. Para tanto, foi desenvolvida uma pesquisa do tipo estado do conhecimento, cuja finalidade assenta-se em mapear, inventariar e descrever a produção científica existente de uma determinada área (FERREIRA, 2002).

Desse modo, foram selecionados periódicos internacionais de categoria A1, segundo web-qualis 2013-2016, cujas temáticas e escopos estivessem relacionados aos esportes de modo geral, uma vez que não se tem registro de revistas específicas sobre a Ginástica Rítmica. Sendo assim, foram consultados 17 periódicos internacionais, dos quais 12 possuíam publicações sobre GR. Com isso, o corpus dessa pesquisa está composto por 28 artigos que têm a Ginástica Rítmica como objeto principal de estudo.

Diante dos resultados produzidos, identificou-se certas incipiências, dentre as quais estão os estudos que se dedicaram a compreender a relação dos saberes profissionais em GR durante a formação inicial em Educação Física. Condição que subsidiou as escolhas metodológicas da segunda fase do estudo, optando-se por realizar uma pesquisa do tipo pesquisa-ação existencial. Para Barbier (2007), essa metodologia, em sua concepção atualizada, 
Os saberes em ginástica rítmica: do mapeamento da produção à formação inicial... Murilo Eduardo dos Santos Nazário • Nicole Cerutti Guirlinzoni

orienta o pesquisador a partir dos problemas levantados pelo grupo pesquisado. Necessita ainda assumir um viés de práxis, no sentido de transformação do lugar e dos sujeitos, dentre eles o próprio pesquisador.

A escolha desse tipo de pesquisa justifica-se devido ao lugar ocupado pela pesquisadora, que também é sujeito do estudo, uma vez que ela está cursando a graduação em Educação Física, é ex-atleta de GR e também tem nessa modalidade um possível itinerário de sua futura atuação profissional. Ademais, as inquietações iniciais do estudo partiram da frustração em relação às poucas experiências oportunizadas pelo curso de Educação Física que ela cursa para a atuação com a GR na especificidade dessa modalidade.

A fim de capturar as subjetividades pessoais sobre essa relação entre formação e saberes profissionais, inicialmente utilizou-se da observação participante, procedimento necessário para transformar o "familiar em exótico e o exótico em familiar" (VELHO, 1978, p. 45).

Em seguida, elaborou-se o diário de itinerância, pois ele se estrutura em torno da tríplice palavra/escuta - clínica, filosófica e poética -, além de evidenciar a relação de envolvimento íntimo e particular que envolve o pesquisador no campo nessa fase do estudo, necessária inclusive à materialização dos registros (BARBIER, 2002). Nessa fase a pesquisadora reaprendeu a observar a organização do curso, analisando inicialmente as disciplinas do currículo e, em seguida, realizou incursões pontuais, com a devida autorização do professor, em disciplinas como GR ( $7^{\circ}$ período), Metodologia dos Esportes Individuais ( $6^{\circ}$ período) e ainda Ginástica Artística ( $8^{\circ}$ período). À medida que os registros e observações se tornavam mais densos, ela também resgatava as suas próprias memórias na $\mathrm{GR}$, anteriormente e durante a graduação.

Em seguida, foram utilizadas, como recurso investigativo, as narrativas autobiográficas. Essas narrativas permitem que o indivíduo não seja silenciado em seu lugar de evidência, mediante o 
Os saberes em ginástica rítmica: do mapeamento da produção à formação inicial... Murilo Eduardo dos Santos Nazário • Nicole Cerutti Guirlinzoni

mergulho em suas memórias, reconstruindo momentos, experiências, além da conexão com sujeitos e objetos. Para Certeau (2002), o processo de rememorização evoca o lugar e o tempo praticado, mas não os isola das inscrições trazidas, pois as artes de contar e as maneiras de fazer estão permeadas de fugas que rompem com a linearidade aparente.

Nessa perspectiva, utilizou-se a entrevista narrativa. Para Jovchelovicth e Bauer (2002), esse tipo de entrevista parte do pressuposto de que cada indivíduo traz consigo palavras e sentidos específicos relacionados com a sua experiência vivida em comunidade, articulando os seus aspectos coletivos e individuais, fundamentais e característicos. A proposta básica da entrevista narrativa é construir acontecimentos sociais com apoio na perspectiva dos sujeitos tão diretamente quanto possível.

O procedimento foi orientado por um roteiro com 10 perguntas, que foram aplicadas junto a 17 alunos, do $1^{\circ}$ ao $8^{\circ}$ períodos, de um curso de Educação Física de uma Instituição de Ensino Superior, no estado do Espírito Santo.

Essa pesquisa foi aprovada pelo comitê de ética da Universidade n. CAAE- 54471616.7.0000.506.

\section{Análise e discussão dos resultados}

\section{ANÁLISE E DISCUSSÃO DOS RESULTADOS DA FASE ESTADO DO CONHECIMENTO}

Foram mapeadas 17 revistas dentro dos padrões estabelecidos, sendo que 12 apresentaram resultados para busca com as palavras chave "Rhythmic Gymnastics", das quais 10 continham artigos tendo a Ginástica Rítmica como tema central de pesquisa. O total de resultados para as palavras-chave foram 262 artigos, sendo que, destes, 28 apresentavam a Ginástica Rítmica como objeto principal de estudo. Para uma percepção melhor do cenário 
Os saberes em ginástica rítmica: do mapeamento da produção à formação inicial... Murilo Eduardo dos Santos Nazário • Nicole Cerutti Guirlinzoni

de pesquisa, desenvolveu-se o Gráfico 1, que reúne as principais revistas que têm publicado estudos sobre a temática.

\section{Gráfico 1 - Resultados para as palavras-chave X Estudos contendo a GR como objeto central de estudo}

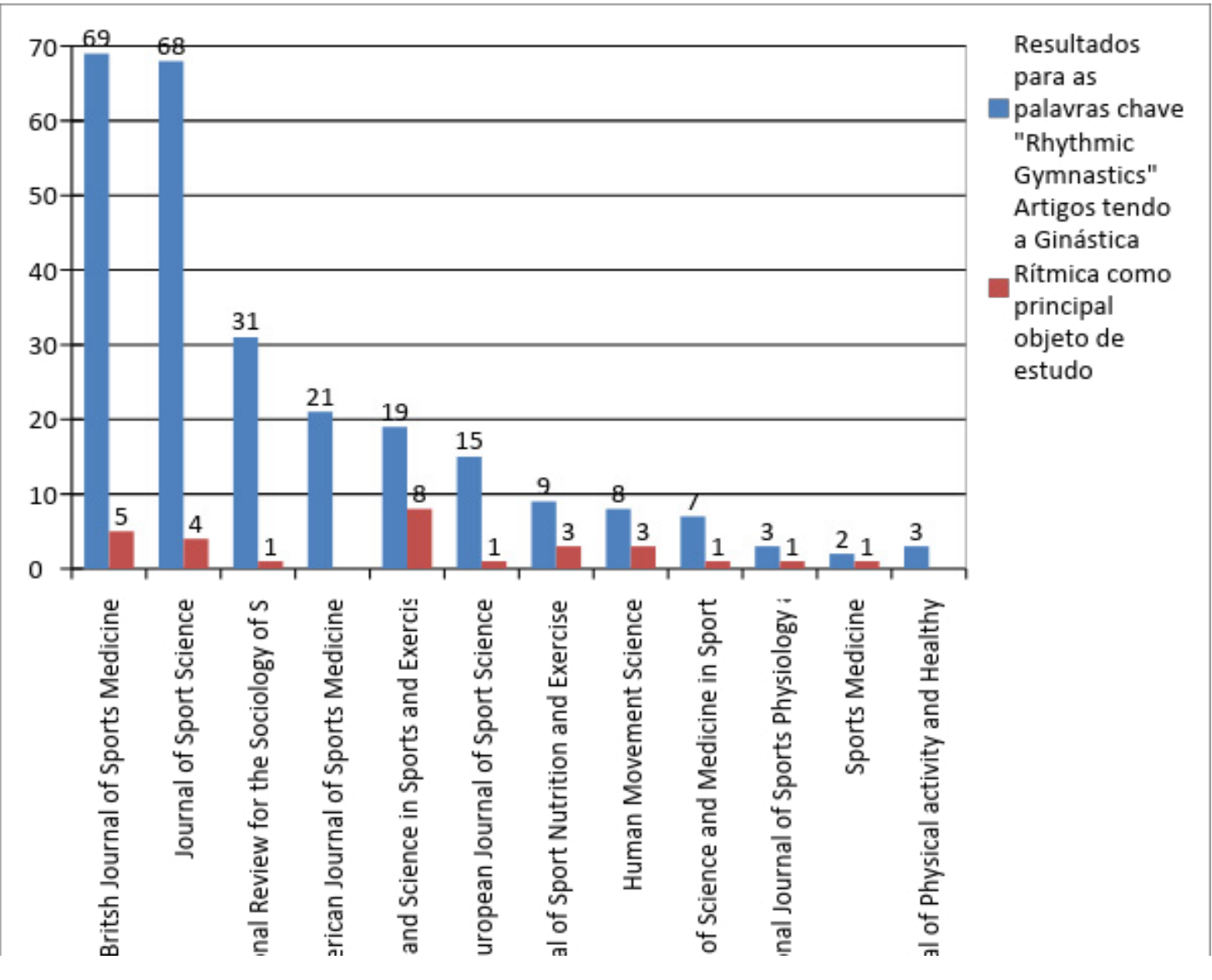

Fonte: elaboração da autora.

Com esse movimento é possível ter uma percepção do campo científico internacional em torno das publicações sobre Ginástica Rítmica. Foi encontrado um número significativo de resultados para as palavras-chave utilizadas, sugerindo que a GR tem sido abordada com certa frequência em estudos do campo esportivo internacional, porém, poucas vezes aparece como objeto principal nas pesquisas que vêm sendo desenvolvidas.

As revistas Britsh Journal of Sports Medicine e Journal of Sport Science apresentaram maior número de resultados para as palavras-chave utilizadas, porém a revista onde foi encontrado maior 
Os saberes em ginástica rítmica: do mapeamento da produção à formação inicial... Murilo Eduardo dos Santos Nazário • Nicole Cerutti Guirlinzoni

numero de artigos com ênfase na GR foi a Medicine and Science in Sports and Exercise, sendo esta uma revista que contém estudos multidisciplinares envolvendo investigações originais, estudos clínicos e revisões compreensivas em tópicos atuais na medicina do esporte e ciência do exercício.

É importante perceber como a produção científica acerca da Ginástica Rítmica se distribui ao decorrer dos anos, com o objetivo de identificar possíveis eventos que possam ter influenciado no número de estudos dentro da área, conforme Gráfico 2.

\section{Gráfico 2 - Recorrência temporal da produção analisada}

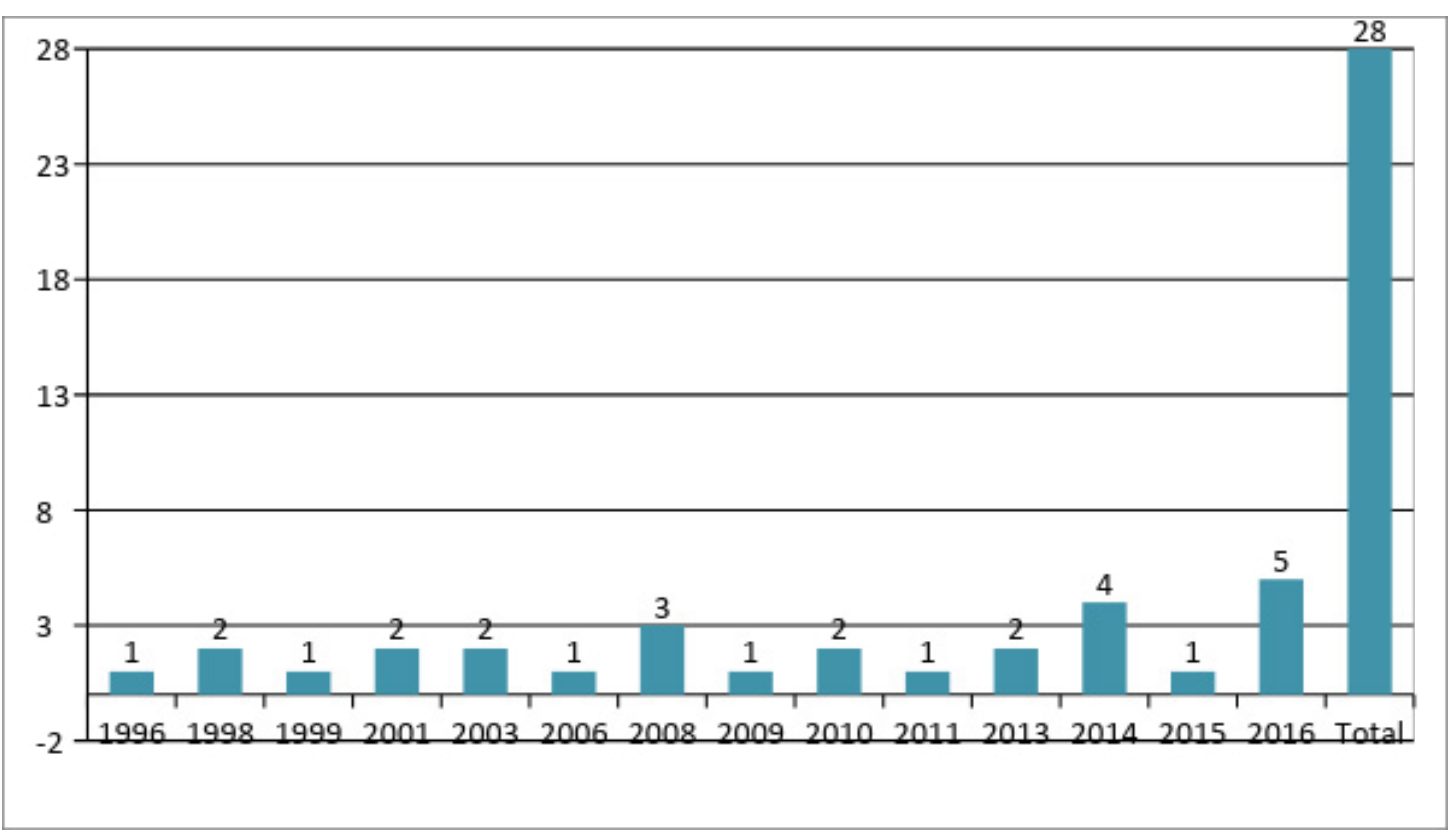

Fonte: elaboração da autora.

Apesar da constante realização de eventos de âmbito internacional envolvendo a Ginástica Rítmica, dentre eles os Jogos Olímpicos de Verão, Campeonatos Mundiais que ocorrem todos os anos e campeonatos internacionais organizados pela Federação Internacional de Ginástica (FIG) múltiplas vezes ao ano, não foi observado nenhum padrão na recorrência temporal das publicações analisadas que sugiram haver alguma relação entre o aumento do número das mesmas e a realização de grandes eventos, embora 
Os saberes em ginástica rítmica: do mapeamento da produção à formação inicial... Murilo Eduardo dos Santos Nazário • Nicole Cerutti Guirlinzoni

haja registro de um aumento no número de publicações no ciclo olímpico 2013-2016.

É preciso ainda analisar os tipos de pesquisas desenvolvidas acerca da Ginástica Rítmica e suas metodologias, com o objetivo de identificar a área de conhecimento e os objetivos dos autores ao desenvolver suas pesquisas. Elementos que ficam mais bem elucidados no Gráfico 3.

\section{Gráfico 3 - Metodologias de Pesquisa utilizadas na produção analisada}

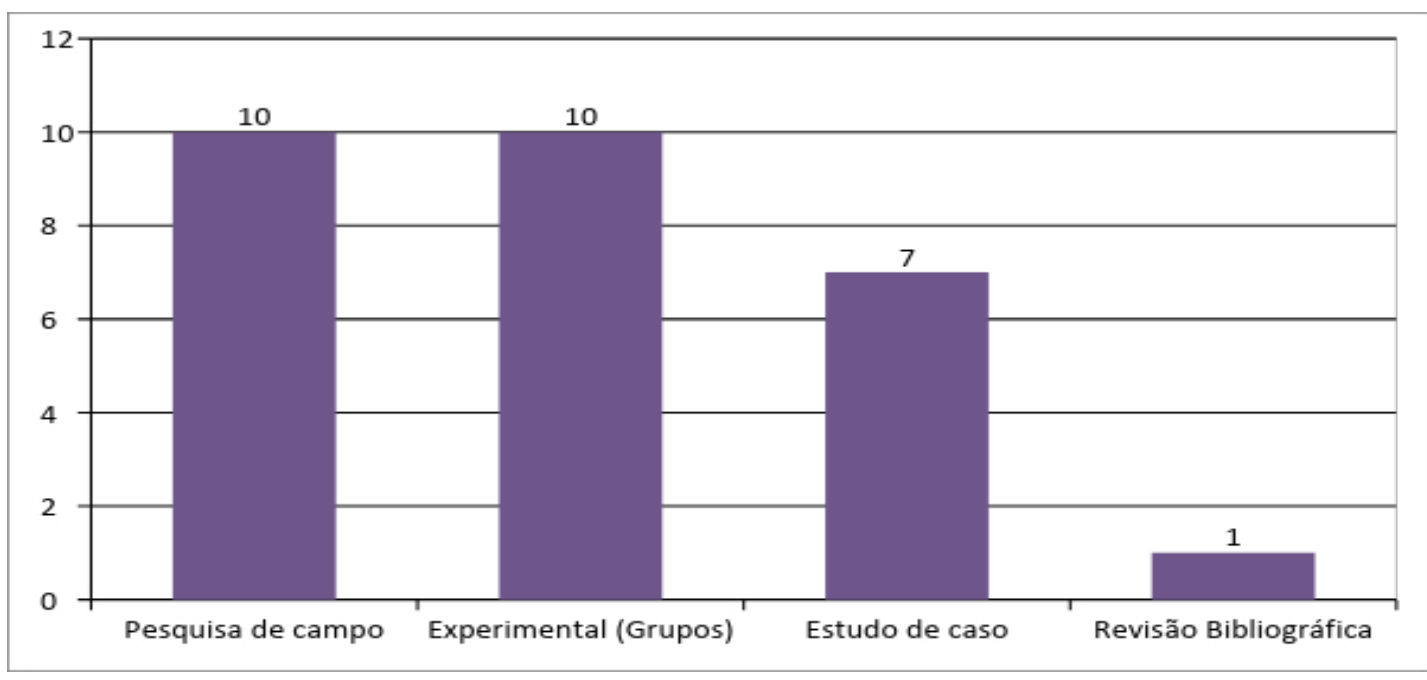

Fonte: elaboração da autora.

Para análise da metodologia de pesquisa, os artigos encontrados foram divididos em categorias estipuladas a partir da natureza dos estudos desenvolvidos. Foram considerados estudos experimentais aqueles que continham a comparação de dois ou mais grupos analisados, sempre contendo um grupo controle. Estudos que analisaram apenas um grupo específico de indivíduos (seleções nacionais, equipes competitivas específicas) foram classificados como estudo de caso. Estudos que não compararam grupos e analisaram indivíduos de maneira generalizada foram classificados como pesquisa de campo. Foi encontrado apenas um estudo de revisão bibliográfica. 
Os saberes em ginástica rítmica: do mapeamento da produção à formação inicial... Murilo Eduardo dos Santos Nazário • Nicole Cerutti Guirlinzoni

É ampla a diferença entre estudos de revisão bibliográfica e pesquisa de campo, incluindo aquelas classificadas como experimentais e estudos de caso, o que sugere uma tendência a explorar o que ainda é desconhecido na área da Ginástica Rítmica e temáticas não anteriormente pesquisadas. Ou seja, é possível dizer que há uma preocupação do campo em desenvolver pesquisas que envolvam as ações da GR.

Assim, é preciso avançar para verificar o tipo de instrumento de coleta de dados que são utilizados nas pesquisas, apresentados no Gráfico 4.

\section{Gráfico 4 - Instrumento de coleta de dados utilizados no desenvolvimento da produção analisada}

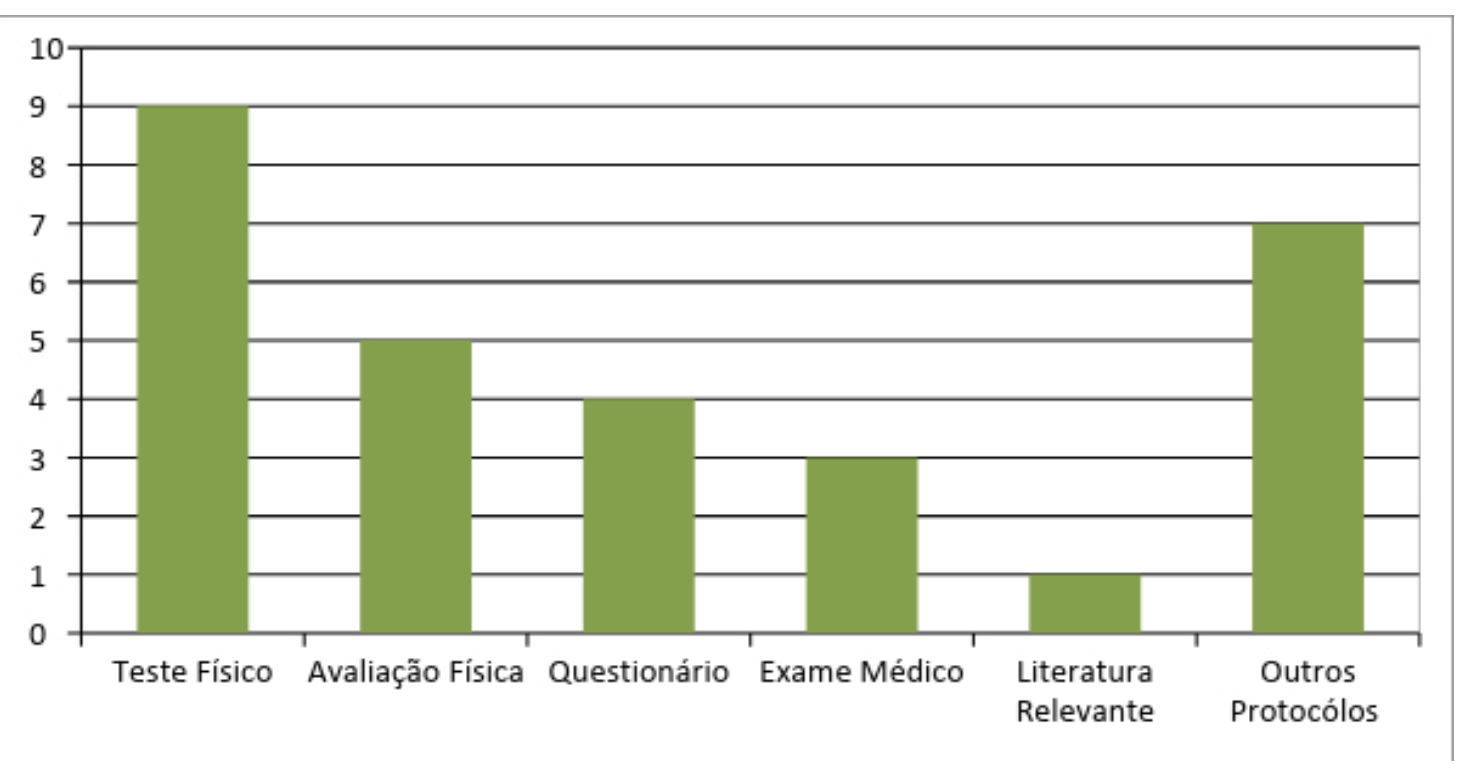

Fonte: elaboração da autora.

Pode-se observar 9 estudos que utilizam testes físicos, sendo esses testes de resistência, potência e flexibilidade como instrumento de coleta de dados, seguidos por testes de avaliação física, questionários e exames médicos. Foi encontrado apenas um estudo que utiliza a literatura relevante como instrumento de coleta de dados, indicando uma carência desse tipo de estudo na área pesquisada. 
Os saberes em ginástica rítmica: do mapeamento da produção à formação inicial... Murilo Eduardo dos Santos Nazário • Nicole Cerutti Guirlinzoni

Não obstante, é necessário analisar os resultados apontados por essas pesquisas. Dessa forma, os resultados que apresentavam proximidade epistemológica foram organizados em categorias temáticas, subsidiando a confecção do Gráfico 5.

\section{Gráfico 5 - Temáticas produzidas pela materialidade textual da produção ana- lisada}

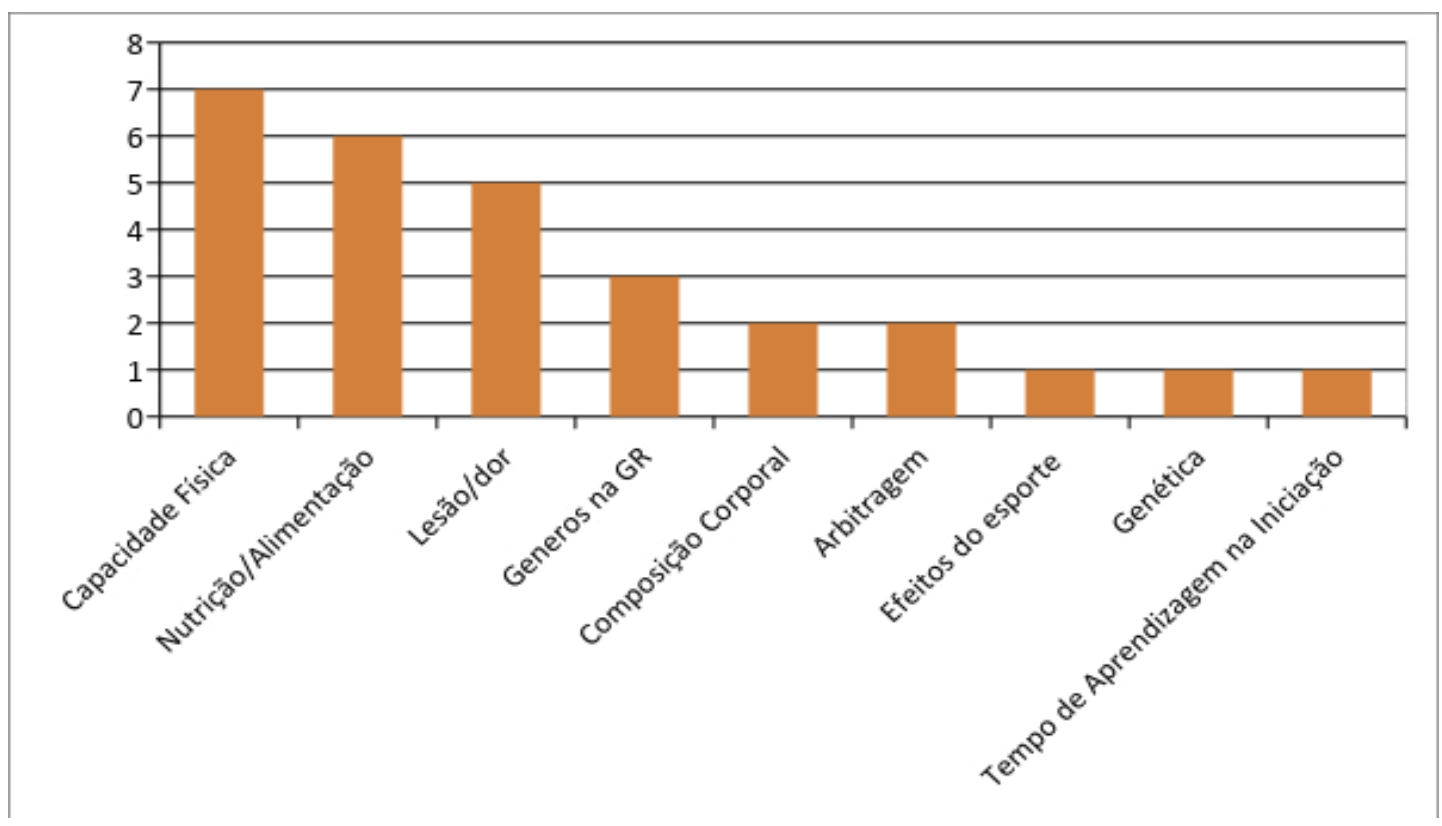

Fonte: elaboração da autora.

Ao analisarmos as temáticas, pesquisas acerca de capacidades físicas tiveram maior incidência, o que sugere uma constante busca por informações que possam vir a colaborar para um treinamento eficiente sob o aspecto das capacidades físicas necessárias à GR, sendo as principais delas, segundo Róbeva e Rankélova (1991), flexibilidade e força.

Dentre as temáticas encontradas é relevante mencionar artigos recentes que têm a diferença de gêneros na GR como problema de estudo, uma vez que a Federação Internacional de Ginástica (FIG) reconhece a GR como esporte exclusivamente feminino, porém esses estudos têm como base mudanças que vêm ocorrendo na modalidade com sua popularização. 
Os saberes em ginástica rítmica: do mapeamento da produção à formação inicial... Murilo Eduardo dos Santos Nazário • Nicole Cerutti Guirlinzoni

Recentemente a tendência de mudança nas diferenças de gênero no esporte introduziu atletas de ambos os gêneros em modalidades antes consideradas de um único gênero (Resolução do Parlamento Europeu no. A50167/2003), e, durante a ultima década, atletas masculinos passaram a se envolver em competições oficiais de GR (DI CAGNO et al., 2009, p. 1, tradução nossa).

É também relevante a presença de estudos acerca da alimentação e nutrição específicas da GR, uma vez que, segundo Porpino (2004), a estética do corpo que se pretende na GR é uma estética centrada no modelo de um corpo esguio e longilíneo, padrão internacional de corpo das ginastas de alto nível. Essa busca por um corpo esguio gera questões alimentares específicas para a modalidade, o que justifica estudos que tratem não da nutrição esportiva como um todo, mas especificamente das questões alimentares da GR.

Temáticas acerca de lesões e dor em atletas de Ginástica Rítmica também se fizeram incidentes, o que sugere a preocupação em investigar as causas das mesmas, possibilitando assim a sua prevenção durante treinamento e competição. Um estudo realizado por Mitija et al. (2016) analisou fatores de risco para lesão na GR e apresentou resultados positivos quando diminuiu o risco de lesão em um grupo de atletas ao implantar treinos de propriocepção de tornozelo na rotina delas, mostrando que os estudos realizados são importantes para solucionar situações problemáticas comumente encontradas na modalidade, contribuindo para o avanço do esporte.

Por outro lado, percebe-se as ausências, também em âmbito internacional de pesquisas relacionadas à formação profissional em Educação Física e à atuação em GR, condição que justifica a segunda fase desta pesquisa. 
Os saberes em ginástica rítmica: do mapeamento da produção à formação inicial... Murilo Eduardo dos Santos Nazário • Nicole Cerutti Guirlinzoni

\section{ANÁLISE E DISCUSSÃO DOS RESULTADOS DA PESQUISA DE CAMPO}

Dessa forma, a materialidade textual produzida a partir das observações participantes, dos registros em diário de itinerância e das entrevistas foi organizada e sistematizada em 3 eixos de análise. A fim de contextualizar os elementos analíticos, extraiu-se fragmentos das narrativas, cuja identificação foi realizada pelas siglas G: (graduando) e N: (número que indica o período do entrevistado).

\section{Trajetória de distanciamentos com os saberes GR}

No primeiro eixo estão reunidos alunos que possuem uma relação de distanciamento com os saberes próprios da GR. Esses estudantes são, principalmente, dos períodos iniciais da graduação em Educação Física.

Assim, surgiram relatos como de G3: "Já vi competições de GR na televisão, mas nunca tive nenhuma experiência ligada a ela. O que sei é que é uma ginástica fora de aparelho fixo" e G2: "Já ouvi falar que algumas competições de GR aconteceriam aqui no estado do Espírito Santo, porém, não me interessei em ir assistilas por não entender a modalidade". E ainda como o de G4: "Eu sei que o estado é um dos melhores do país. Tem aquela menina que foi da seleção (Natália Galdio)." Elementos que sugerem alguma visibilidade à modalidade, a ponto de alcançar alguns graduandos, porém essa aproximação não se confirma no campo do uso e consumo produtivo (CERTEAU, 2002) no/com/o corpo.

Esse afastamento pode estar relacionado à ausência das inserções significativas de aprendizagem produzidas pelos saberes experienciais (TARDIFF, 2002), desenvolvidos em contextos como o escolar e/ou da iniciação esportiva. Do mesmo modo, na graduação, em que poderia-se produzir relações com os saberes da GR a partir dos saberes disciplinares (TARDIFF, 2002) principalmente, isso não ocorre no contexto pesquisado devido à condição da disciplina específica ser ofertada somente a partir do $7^{\circ}$ período. 
Os saberes em ginástica rítmica: do mapeamento da produção à formação inicial... Murilo Eduardo dos Santos Nazário • Nicole Cerutti Guirlinzoni

Outro ponto que contribui com esse cenário relaciona-se à falta de projetos de extensão voltados a essa modalidade, aspectos que colaboram para perpetuar esse afastamento em relação à GR.

Durante o período de observação, e ao resgatar as suas memórias mais significativas, a pesquisadora percebeu que outras matérias da grade curricular poderiam realizar essas aproximações com a prática da GR, tais como: Metodologia do Esportes Individuais $\left(6^{\circ}\right.$ período), Aprendizagem Motora ( $3^{\circ}$ período), Didática ( $5^{\circ}$ período), mesmo que sem os aprofundamentos, progressões e sistematizações específicas da modalidade. Todavia, no contexto pesquisado não há direcionamentos pedagógicos para essa modalidade nas disciplinas listadas. Elementos que, por sua vez, contribuem para o distanciamento da GR como um espaço de atuação profissional e, não obstante, para seu ensino, por exemplo, no âmbito escolar.

Estudos como de Betti (1999), Rosário e Darido (2005) sugerem que, conteúdos com os quais professores têm pouca afinidade e/ ou vivência, dificilmente serão incorporados ao cotidiano de suas aulas. Ademais, pode-se inferir que no campo do bacharelado, na condição de treinador, a GR sofre um significativo afastamento, pois não se apresenta como lugar próximo e/ou possível de exercício profissional, pressupostos que colaboram para a perpetuação de um ciclo de ausências e distanciamentos em relação às experiências com essa modalidade.

\section{Aproximações com os saberes disciplinares da GR}

Este eixo é formado pelos graduandos que apresentam conhecimentos básicos sobre a modalidade, composto principalmente por alunos de $7^{\circ}$ e $8^{\circ}$ períodos, além da pesquisadora.

Alguns trechos das narrativas colaboram para compreender esse tipo de relação com a GR. O aluno G7: "Sei que é a ginástica realizada com coreografias e dança". Outros relatos apresentam mais conhecimento sobre a modalidade: "Os aparelhos seriam 
Os saberes em ginástica rítmica: do mapeamento da produção à formação inicial... Murilo Eduardo dos Santos Nazário • Nicole Cerutti Guirlinzoni

bola, fita e maças", como o de G8, e o de G82: "Tem modalidade individual e em grupo com 5 integrantes".

Identificou-se que as apropriações dos saberes e suas inscrições (CHARLOT, 2000) em relação à GR, entre esses graduandos, são provenientes daqueles de natureza disciplinar (TARDIFF, 2002). $\mathrm{Na}$ grade curricular da instituição é ofertada aos alunos a cadeira de GR no $7^{\circ}$ período, com carga horária de 40 horas semanais. Todavia, são oferecidas outras disciplinas que possuem 80 e 60 horas. A opção de, tanto a GR quanto a Ginástica Artística (GA), serem organizadas com essa carga horária relaciona-se, segundo o coordenador do curso ${ }^{2}$, ao projeto curricular que entende que essas matérias seriam de aprofundamento, para treinamento e aperfeiçoamento de ensino. Com isso, ficaria a cargo da disciplina Metodologia dos Esportes Individuais (MEI) a introdução e iniciação aos conhecimentos básicos dessa modalidade e outras de mesma natureza. No entanto, os alunos entrevistados, bem como nas memórias evocadas pela pesquisadora, atribuem outra finalidade a essa disciplina, a de compartilhar práticas esportivas individuais, como bodyboard, skate, tênis de campo, tênis de mesa, para citar alguns dos vivenciados que não possuíam disciplina própria no currículo da instituição. Aspecto que fica melhor exemplificado no descrito pelo G6, aluno que cursava a matéria de MEI, "Até o momento não tivemos nenhuma prática de GR ou GA [...] Acho que só teremos no $7^{\circ}$ ou $8^{\circ \prime \prime}$.

Os relatos também evidenciam certa ambiguidade no que se refere à realização dos estágios supervisionados, pois os mesmos são oferecidos entre o $5^{\circ}$ e $8^{\circ}$ períodos, ou seja, dificilmente os graduandos introduzem no cotidiano de seus saberes/fazeres, práticas relacionadas à GR. Aspecto que é narrado por G8: “Acho que a GR e a GA poderiam vir em um outro período, que fosse antes ao estágio, pra gente exercitar o que é aprendido". Que continua com G7: "Vontade eu até tenho, mas o que tive na matéria, não me dá essa segurança. Tenho muito receio". Assim, pode-se inferir que se o graduando possui uma relação de aproximação com essa moda-

2 Ele não foi entrevistado, esse fragmento refere-se ao período da observação em que a pesquisadora, durante uma das disciplinas que ele ministra, fez essa indagação. 
Os saberes em ginástica rítmica: do mapeamento da produção à formação inicial... Murilo Eduardo dos Santos Nazário • Nicole Cerutti Guirlinzoni

lidade, possivelmente ele a incorpora como uma possibilidade didático-pedagógica. Aspecto que se confirma, quando se compara à pesquisadora do estudo, pois em seu estágio na educação infantil, organizou ações didático-pedagógicas em GR a partir de suas escolhas e sugestões, sem necessitar de orientação do professor supervisor ou professor colaborador.

Esse distanciamento produz também um desinteresse em procurar locais que ofereçam ensino-aprendizagem e treinamento em GR no campo do Bacharelado, pois a instituição tem parceria com um projeto que oferece essa modalidade para crianças e adolescentes. Porém, os alunos entrevistados disseram que prefeririam realizar o estágio do campo do esporte em outras modalidades, como tênis de campo, basquete, futebol e corrida de rua, pois entendem que o mercado profissional tem mais oportunidades para essas práticas corporais. E no caso da pesquisadora, ela optou por realizá-lo em um espaço diferente, no caso, em um projeto de esportes coletivos, com intuito de ampliar suas experiências de atuação como treinadora.

\section{Aproximações aos saberes experienciais e disciplinares em GR}

No terceiro eixo, a principal diferenciação, em relação ao grupo de graduandos da segunda categoria, refere-se à apropriação dos saberes em GR também por experiências (TARDIFF, 2002) anteriores à disciplina ou ao ingresso em um curso superior. Porém, entre os sujeitos, somente a pesquisadora possui uma trajetória cronológica significativa com a GR, cerca de 13 anos, que abrangem iniciação esportiva e competições em nível estadual e nacional. Os outros entrevistados disseram que quando eram crianças fizeram por alguns meses, como G2: "Eu fiz quando era bem pequena, devia ter uns 7 anos. E acho que não fiz nem um ano. Mas lembro de alguns exercícios". Ou vivenciaram experiências na família, como G7: "Minha irmã fazia e a gente ia ver ela durante as competições aqui em Vix". 
Os saberes em ginástica rítmica: do mapeamento da produção à formação inicial... Murilo Eduardo dos Santos Nazário • Nicole Cerutti Guirlinzoni

Entre os saberes que os graduandos sinalizam como mais significativos para a atuação profissional com a GR estão aqueles vinculados aos conhecimentos das técnicas e às capacidades físicas dessa modalidade. G8 cita que as capacidades físicas "flexibilidade, força e equilíbrio são as mais importantes, na minha opinião". Para G7: "Resistência, força e flexibilidade são as capacidades básicas que precisamos na maioria das modalidades, em maior ou menor proporção". G7: "Quando você consegue ensinar a criança a fazer o Véu ou os Pivots, ou mesmo jogar e receber a bola, é gratificante. Porque você sabe como é difícil fazer esses movimentos." Assim, ao aprender e familiarizar-se com esses movimentos, eles consideram que é possível ensinar esse conteúdo ou qualquer outro, seja na escolinha, seja na escola. Desse modo, hierarquizam as aprendizagens necessárias, atribuindo ao componente técnico e ao físico status de estruturas primordiais de aprendizagem.

Esses aspectos convergem, junto à literatura analisada, para a superioridade do número de estudos ligados à prescrição do treinamento físico. Com isso, os saberes pedagógicos, metodológicos e voltados para o desenvolvimento humano são por vezes secundarizados, pressupostos que devem ser melhor observados pelo campo científico da GR para estudos futuros.

Outro ponto a ser destacado é que os alunos se sentem inseguros para organizar a progressão e sistematização de um processo de ensino-aprendizagem e treinamento na GR a longo prazo, pois utilizam de apropriações advindas dos conhecimentos didático-pedagógicos gerais de outras matérias, sendo comum relatos como de G7: "O trabalho seria feito de forma progressiva, partindo do fácil pro difícil, do simples para o complexo, porém para saber o que trabalhar, para competição, com uma turma de ginástica eu precisaria de um curso de especialização". Ou G7: "Acho que ensinar os movimentos da GR, consigo. A gente aprende aqui, algumas didáticas, para ensinar o básico". Já para G8: "Entraria em contato com alguém que tem experiência na área para me ajudar com o conteúdo a ser trabalhado". 
Os saberes em ginástica rítmica: do mapeamento da produção à formação inicial... Murilo Eduardo dos Santos Nazário • Nicole Cerutti Guirlinzoni

É importante considerar, a partir da leitura positiva (CHARLOT, 2000), que as narrativas expressam a capacidade desse profissional em formação de apresentar ideias coerentes com princípios da iniciação e treinamento esportivo, ou mesmo para compartiIhamentos pedagógicos iniciais. Do mesmo modo, averigua-se que os graduandos consideram que a complexidade do trabalho pedagógico, em alguns contextos, requer deles uma preparação mais ampla. Elementos que se coadunam ao processo de apropriação do saber.

De acordo com Charlot (2000), o aprendizado de um conhecimento ocorre ao exercer uma atividade em situação e por meio das/nas relações com as figuras do aprender. Organizados de modo imbricado pela objetivação-denominação, imbricação do Eu na situação e distanciação-regulação. O primeiro envolve a relação iniciação de aproximação a um conhecimento que ainda não se tem, presente em pessoas, objetos e lugares. No segundo momento, ocorrem as inscrições iniciais de uma apropriação desse aprender até então afastado. Já no último, é possível compreender as marcas da apropriação de domínio desse saber em uma relação que envolve a si mesmo, os outros e o mundo.

Charlot (2000), sobre as relações com o saber e as figuras do aprender, compreende que a Educação Física valoriza o saber de imbricação do eu em situação que ocorre no domínio de uma atividade e tem o corpo como lugar de apropriação do mundo; e o saber produzido pela distanciação-regulação, que se refere ao aprender pelos relacionamentos e situações, pelo domínio de uma relação recíproca com os sujeitos. Sendo assim, para o graduando dessa área, a coerência de sua ação de compartilhamento de saber também está vinculada a uma apropriação relevante na sua condição como professor em formação. Pressupostos que podem indicar esses possíveis desinteresses e afastamentos em relação à atuação profissional em Educação Física no campo da GR. 
Os saberes em ginástica rítmica: do mapeamento da produção à formação inicial... Murilo Eduardo dos Santos Nazário • Nicole Cerutti Guirlinzoni

\section{Considerações Finais}

Os resultados encontrados sugerem uma condição incipiente no que tange à relação dos graduandos em educação física com os saberes da Ginástica Rítmica, condição proveniente da ausência de experiências sistematizadas de ensino aprendizagem e treinamento com essa modalidade, antes e durante a graduação.

Dentre os saberes evocados pelos graduandos, necessários à atuação profissional em Ginástica Rítmica, destacam-se os conhecimentos técnicos e aqueles voltados ao treinamento das aptidões físicas. Todavia, consideram insuficientes as 40 horas da disciplina, bem como as experiências oferecidas pela Universidade, para a organização e o desenvolvimento de um processo de ensino-aprendizagem e treinamento a longo prazo.

Nesse sentido, é possível sinalizar que a organização curricular, principalmente do curso de Educação Física em questão, necessita localizar de modo mais significativo o lugar da GR em seu projeto de formação inicial. Para isso, a curto prazo, pode-se repensar a ementa da própria disciplina de $\mathrm{MEI}$, a fim de oportunizar experiências de aprendizagem básicas com a modalidade, deixando a cargo da disciplina específica os aprofundamentos necessários para ensino-aprendizagem e treinamento. Ainda, sugere-se a implantação de projetos de extensão vinculados à modalidade, para que, a partir dele, sejam produzidas pesquisas nessa área.

Não obstante, mostrou-se profícua a opção metodológica do estudo, partindo das lacunas, como elemento norteador da fase da pesquisa empírica. Esse tipo de ação colabora para avanços em termos epistemológicos. No presente caso, para campos emergentes na GR, evitando modismos, reducionismos próprios de uma área. 
Os saberes em ginástica rítmica: do mapeamento da produção à formação inicial... Murilo Eduardo dos Santos Nazário • Nicole Cerutti Guirlinzoni

\section{Referências}

BARBIER, R. A pesquisa-ação. Brasília: Editora Plano, 2007.

BARROS, J. M. de C. Educação Física na Unesp de Rio Claro: bacharelado e licenciatura. Motriz, Rio Claro, v.1, n. 1, p. 71-80, 1995.

BAXTER-JONES, A. D. G.; MAFFULLI, N. Parental influence on sport participation in elite young athletes. Journal of sports medicine and physical fitness, v. 43, n. 2, p. 250, 2003.

BELÃO, M.; MORI, P. M. M.; MACHADO, L. P. A formação profissional das técnicas de ginástica rítmica. Motriz rev. educ. fís. (Impr.), v. 15, n. 1, p. 61-68, 2009.

BETTI, I. R. C. Esporte na escola: mas é só isso, professor? Motriz - Volume 1, Número 1, 25 -31, junho/1999.

BORGES, C. N. F.; TONINI, G. T.. O incentivo ao esporte de alto rendimento como política pública: influências recíprocas entre cidade e esporte. Revista Brasileira de Ciências do Esporte, $v$. 34, n. 2, 2012.

CERTEAU, Michel de. A invenção do cotidiano: 1. artes do fazer. 15. ed. Petrópolis: Vozes, 2002.

CHARLOT, B. Da relação com o saber: elementos para uma teoria. Porto Alegre: Artes Médicas Sul, 2000.

FERREIRA, N. S. de A. "As pesquisas denominadas" estado da arte. Educação \& sociedade, v. 23, p. 257.

PORPINO, K. de O. Treinamento da ginástica rítmica: reflexões estéticas. Revista Brasileira de Ciências do Esporte, v. 26, n. 1, 2004.

DI CAGNO, A. et al. Factors influencing performance of competitive and amateur rhythmic gymnastics-Gender differences. Journal of Science and Medicine in Sport, v. 12, n. 3, p. 411-416, 2009.

DRIGO, A. J.; SOEIRO, M. I. P.; CESANA, J. Intervenção Profissional: limites e possibilidades In: SOUZA NETO, S.; HUNGER, D. (Orgs). 
Os saberes em ginástica rítmica: do mapeamento da produção à formação inicial... Murilo Eduardo dos Santos Nazário • Nicole Cerutti Guirlinzoni

Formação Profissional em Educação Física: estudos e pesquisas. Rio Claro: Biblioteca, p. 251-256, 2006.

GAIO, R.; BATISTA, J. C. de F.. Ginástica Ritmica “Popular”: uma proposta educacional. $2^{\mathrm{a}}$ edição, Jundiaí: Fontoura, 2007.

JOVCHELOVITCH, S.; BAUER, M. W. Entrevista narrativa. In: BAUER M. W.; GASKELL, G. G. (Org.). Pesquisa qualitativa com texto, imagem e som: um manual prático. Petrópolis, Editora Vozes, p. 64-73. 2002.

LANARO FILHO, P.; BÖHME, M. T. S. Detecção, seleção e promoção de talentos esportivos em ginástica rítmica desportiva: um estudo de revisão. Revista Paulista de Educação Física, v. 15, n. 2, p. 141-153, 2017.

MITIJA, S. P. et al. 0-46 The effect of ankle proprioception training on injury risk in rhythmic gymnastics. British Journal Sports of Medicine, v. 50. I. Suppl. 1, 2016.

PEREIRA, A. M.; ANDRADE, T. N.; CESÁRIO, M. A produção do conhecimento científico em ginástica. Conexões, v. 10, 2012.

RÓBEVA, N.; RANKÉLOVA, M. Escola de campeãs: ginástica rítmica desportiva. Tradução Geraldo Moura. São Paulo: ícone, 1991. ROSÁRIO, L.F.R. DARIDO, S.C. A sistematização dos conteúdos da educação física na escola: a perspectiva dos professores experientes. Motriz, Rio Claro, v.11 n.3 p.167-178. 2005.

SANTOS, E. V. N. dos; LOURENÇO, M. R. A.; GAIO, R. “Composição coreográfica em ginástica rítmica: do compreender ao fazer." Jundiaí, SP: Fontoura, 2010.

TARDIF, Maurice. Saberes docentes e formação profissional. $4^{\mathrm{a}}$ Ed. Rio de Janeiro: Vozes, 2002.

VELHO, G. Observando o familiar. In: NUNES, E.O. (Org.) A aventura sociológica: objetividade, paixão, improviso e método na pesquisa social. Rio de Janeiro: Zahar editores, 1978. 
Os saberes em ginástica rítmica: do mapeamento da produção à formação inicial... Murilo Eduardo dos Santos Nazário • Nicole Cerutti Guirlinzoni

\section{Aprovação de comitê de ética em pesquisa}

Pesquisa aprovada pelo Comitê de Ética da Universidade Vila Velha - UVV/ES. Título: Formação profissional em Educação Física: entre reflexões e práticas.

\section{Publisher}

Universidade Federal de Goiás. Faculdade de Educação Física e Dança. Publicação no Portal de Periódicos UFG. As ideias expressadas neste artigo são de responsabilidade de seus autores, não representando, necessariamente, a opinião dos editores ou da universidade. 